\title{
LA RESPONSABILIDAD CIVIL MÉDICO-SANITARIA EN EL ORDENAMIENTO JURÍDICO CHILENO*
}

\author{
HEALTH MEDICAL CIVIL RESPONSIBILITY IN THE CHILEAN \\ LEGAL STSTEM
}

\author{
Carolina Riveros FERRADA** \\ Maximiliano Olivares RAMÍREZ**** \\ Gabriela VILLARROEL TORO****
}

RESUMEN: La Ley 19.996, también conocida como Ley AUGE, consagró un régimen de garantías de salud. En ese sentido, es relevante analizar el régimen de responsabilidad que recae sobre los prestadores de salud y las particularidades que nuestro ordenamiento jurídico establece en estos casos.

Palabras clave: Salud, política social, responsabilidad civil, responsabilidad médica, mediación.
ABSTRACT: Law 19.996, also known as the AUGE Law, created a system of health guarantees In this sense, it is relevant to analyze the regime that regulates on the health providers and the particularities that our legal system establishes in these cases.
Keywords: Health, public policy, civil liability, medical responsibility, mediation.

* Artículo recibido el 29 de marzo de 2019 y aceptado para su publicación el 9 de diciembre de 2019. Este artículo de reflexión forma parte del proyecto de investigación Proyecto Anillo sobre "Mecanismos alternativos de resolución de conflictos como herramienta de modernización de la justicia. Construcción dogmática a partir de un análisis multidisciplinario", financiado por Conicyt (SOC 1406), Chile, del cual participo en la calidad de coinvestigadora.

** ORCID: 0000-0001-8435-3206. Adscrita al Departamento de Derecho Privado y Ciencias del Derecho de la Facultad de Ciencias Jurídicas y Sociales de la Universidad de Talca, Chile. Correo electrónico: criveros@utalca.cl.

*** ORCID: 0000-0003-2858-7299. Licenciado en Ciencias Jurídicas y Sociales, Universidad de Talca, Chile. Correo electrónico: maxolivares@utalca.cl.

***** ORCID: 0000-0002-3913-7966. Egresada de Derecho, Universidad de Talca, Chile. Correo electrónico: gvillarroel@gmail.com.

Boletín Mexicano de Derecho Comparado, nueva serie, año LI, núm. 156, septiembre-diciembre de 2019, pp. 1575-1598. 
SUMARIO: I. Introducción. II. Responsabilidad en el ámbito sanitario. III. Características de la responsabilidad civil en el ámbito sanitario. IV. Notas particulares de la responsabilidad médico-sanitaria. V. De la pérdida de la oportunidad como responsabilidad sanitaria VI. Conclusiones. VII. Referencias bibliográficas.

\section{INTRODUCGIÓN}

En atención a lo dispuesto en el artículo 43 de la Ley 19.966, la mediación sanitaria se circunscribe a prestadores de carácter público y privado para "obtener la reparación de los daños ocasionados en el cumplimiento de sus funciones de otorgamiento de prestaciones de carácter asistencial". Interesa estudiar la regulación que la legislación chilena determina respecto de la reparación de daños y los supuestos que se encuentran cubiertos, para contextualizar de qué manera la mediación obligatoria interviene y sobre qué circunstancias se aplica para darle el valor real que posee como mecanismo alternativo de solución de conflictos, cuestión a la que nos hemos referido en el texto denominado "Ventajas de la mediación en el ámbito sanitario y su ampliación a otros tópicos".

Ahora bien, el concepto de responsabilidad se posiciona como uno de los pilares fundamentales del derecho, puesto que impone a los particulares la obligación de hacerse cargo de sus acciones u omisiones y las consecuencias que de ellas pueden derivar. Desde una perspectiva jurídica, el concepto de responsabilidad se ha entendido por la doctrina chilena como aquella que

...consiste en el deber de indemnizar los perjuicios causados por el incumplimiento de una obligación preexistente. Esta obligación puede derivar de una relación contractual, o del deber genérico de comportarse con prudencia y diligencia en la vida de relación, o de un mandato legal explícito (Rodríguez 2012, 10 y 11).

La definición transcrita es aceptada de forma unánime tanto por la doctrina como por la jurisprudencia nacional, y de ella se desprenden los dos principales tipos de responsabilidad: la contractual y la extracontractual. La primera de ellas emana del incumplimiento total o parcial de las obligaciones establecidas en un contrato que antecede los servicios que van a prestarse, mientras que la segunda nace en virtud de la transgresión 
de un deber general de cuidado con el que las personas deben actuar en el desarrollo de sus actividades.

A pesar de que puedan existir similitudes entre ambos estatutos, es necesario plantear que ambos implican una hipótesis contrapuesta, que debe necesariamente ser analizada de manera separada la una de la otra. De tal forma, los presupuestos ${ }^{1}$ de la responsabilidad contractual han sido sistematizados como los siguientes: existencia de obligación contractual, incumplimiento de la obligación del deudor, que el incumplimiento esté acompañado de un reproche objetivo o subjetivo del obligado, que la omisión de la conducta cause daño al acreedor y que exista una relación de causa a efecto entre el incumplimiento y el daño (Rodríguez 2012, 28).

Así, el elemento característico de la responsabilidad contractual implica la necesaria vinculación entre la víctima y el autor del hecho u omisión dañoso producto del incumplimiento de sus obligaciones. Existe consenso en que el incumplimiento de las obligaciones implica su inejecución, ya sea total o parcial, pero también que la prestación sea realizada de manera tardía, según suponga el caso en cuestión.

A su turno, la responsabilidad extracontractual presenta los siguientes presupuestos: un hecho o acto originado en la voluntad del ser humano, que tenga un carácter injusto o ilícito desde un punto de vista objetivo, que este hecho o acto haya causado un daño existiendo un vínculo causal entre este y el perjuicio, debe ser imputable a una persona según el sistema de responsabilidad que se haga valer (Corral 2011, 106 y 107).

La existencia de un deber general de cuidado en las acciones que guían a las personas caracteriza a la responsabilidad extracontractual,

1 Este criterio ha sido replicado por la jurisprudencia en sentencia de la Corte Suprema rol 8235-2015 del 9 de marzo de 2016, que en su considerando tercero señala: "La doctrina tradicional señala como requisitos para la procedencia de la indemnización de perjuicios en materia contractual: a) la infracción de la obligación, sea por no haberse cumplido o porque se ha cumplido en forma imperfecta o tardía (artículo 1556 del Código Civil), b) la imputabilidad de los perjuicios al deudor, o sea, que ellos se daban a su culpa o dolo y no a hechos extraños, como la fuerza mayor o el caso fortuito, c) la interpelación hecha por el acreedor al deudor, esto es, que lo haya constituido en mora, y d) que la infracción de la obligación origine perjuicios al acreedor". En el mismo sentido, Sentencia de la Corte de Apelaciones de Santiago rol 14229-2017 del 18 de diciembre de 2018, considerando cuarto: "Que, como se sabe, constituyen presupuestos de la responsabilidad contractual: un contrato válido que vincule a las partes; la existencia de daño ocasionado por una de ellas en perjuicio de la otra; y que el daño provenga del incumplimiento de una obligación contractual". 
lo que implica entonces la ausencia de una relación contractual previa. De todas formas es necesario tener presente que esta afirmación ha sido sobrepasada por la práctica judicial, en que comúnmente se interponen ambas acciones, una en subsidio de otra, principalmente por las razones que se analizarán en las notas particulares de la responsabilidad médicosanitaria.

Éste es el panorama general de la legislación chilena en cuanto a la responsabilidad desde una óptica global; sin embargo, no existe en nuestra legislación un estatuto que regule de manera particular la responsabilidad en el ámbito sanitario, pero las características propias de los litigios que versan sobre la materia tienen necesariamente diversas peculiaridades, que generan un tratamiento especial y que justifican desde nuestra perspectiva la utilización de la mediación sanitaria obligatoria.

De tal modo, a la existencia de dos posibles estatutos que las víctimas de un hecho dañoso pueden utilizar, es necesario añadir una distinción previa según si el que se imputa como responsable de las consecuencias que han generado un perjuicio sea un prestador público o privado. De tal forma, profundizaremos el estudio de la responsabilidad en el ámbito sanitario.

\section{RESPONSABILIDAD EN EL ÁMBITO SANITARIO}

La responsabilidad médico-sanitaria en Chile puede ser analizada desde diferentes perspectivas; así, puede ser estudiada la responsabilidad penal, administrativa y de carácter civil. Asimismo, también puede ser clasificada según a quiénes se les entienda responsables, a saber: a los profesionales de la salud, tanto médicos como otros profesionales sanitarios; las instituciones sanitarias, como centros médicos u hospitales, y, en tercer lugar, las autoridades sanitarias del Estado; de este modo, todos los posibles involucrados son relevantes, puesto que, en definitiva, podría responder inclusive el Estado por la falta de servicio.

Se excluye en este análisis la responsabilidad penal y de carácter administrativo, ya que los casos de mediación sanitaria se refieren a casos de responsabilidad civil. También se excluye del presente análisis el estatuto de protección a los derechos de los consumidores, puesto que respecto de los servicios de salud existe una exclusión expresa en el literal f del ar- 
tículo 2o. de la Ley 19.946 . $^{2}$ Por lo tanto, la disposición respecto de la mediación sanitaria obligatoria contenida en el artículo 43 de la Ley 19.996 se aplicará exclusivamente respecto de las pretensiones indemnizatorias conforme a las reglas de la legislación civil chilena. De todas formas, es relevante destacar que en la historia de la ley se declara que el fin de esta exclusión tuvo como objetivo central evitar la judicialización de los conflictos que puedan presentarse en materia de salud (Nasser 2014, 78 y 79). A pesar de la fundamentación entregada en la discusión parlamentaria, no estamos de acuerdo con la medida adoptada por el legislador en estos casos, que excluye en términos absolutos las discusiones que, de manera más que justificada, pueden verse relacionadas con problemas del consumidor.

No obstante ello, se ha generado una interpretación que permitiría aplicar la ley del consumidor a un tipo de contrato específico, relacionado con intervenciones corporales con fines de embellecimiento. Los argumentos que permitirían la aplicación tienen como eje central la comprensión de lo que implica una intervención de embellecimiento que:

A pesar de encontrarse dentro del ámbito de la salud, soy de la opinión de que las intervenciones estéticas al cuerpo no son prestaciones de salud, que es la principal exclusión del art. 2o., pues no se dirigen al restablecimiento de ella. La "salud" debe entenderse en estas materias en sentido estricto; esto es, como un estado en que el ser orgánico ejercer normalmente todas sus funciones. Quienes se someten a una intervención quirúrgica con fines cosméticos (guiados por modelos de belleza de moda), se caracterizan, o bien por no tener un funcionamiento orgánico "anormal", o bien si lo tienen, por no estar dirigida la acción de embellecimiento a la solución de la disfunción que puedan presentar (no es la terapia) (Rosso 2012, 611).

2 Ley que establece normas sobre la protección de los derechos de los consumidores, publicada en el Diario Oficial del 7 de marzo de 1997: "Artículo 2o. Quedan sujetos a las disposiciones de esta ley: f) Los actos celebrados o ejecutados con ocasión de la contratación de servicios en el ámbito de la salud, con exclusión de las prestaciones de salud; de las materias relativas a la calidad de éstas y su financiamiento a través de fondos o seguros de salud; de la acreditación y certificación de los prestadores, sean éstos públicos o privados, individuales o institucionales y, en general, de cualquiera otra materia que se encuentre regulada en leyes especiales". 


\section{CARACTERÍSTICAS DE LA RESPONSABILIDAD GIVIL EN EL ÁMBITO SANTIARIO}

El tratamiento que el Código Civil chileno da a la responsabilidad ha supuesto una dificultad en su aplicación para casos más complejos, pues el desarrollo ha quedado entregado a la doctrina, que se ha esforzado por aplicar las normas a diversos supuestos de hecho, y la jurisprudencia, que ha delimitado y entregado determinadas pautas sobre la materia. $\mathrm{Al}$ efecto, nos centraremos en tres pares antinómicos que han dominado la discusión de la responsabilidad de los profesionales de la salud.

\section{1. ¿Responsabilidad extracontractual o contractual?}

La primera dificultad que se nos presenta es qué régimen de responsabilidad aplicar (Parra 2014). La disyuntiva no es irrelevante, puesto que las diferencias entre uno y otro determinan la estrategia judicial a seguir, y han sido apuntadas por la doctrina, reconociendo como las principales: la existencia de gradación de la culpa en materia contractual, diferencias probatorias, la necesidad de constitución en mora en la responsabilidad contractual, presencia de responsabilidad solidaria en materia extracontractual, regulación de la prescripción diferente en ambos casos, entre otras diferencias relevantes (Barros 2010).

El estatuto contractual, que podría sostenerse que es la visión más clásica del fenómeno, ha sido abordado en las sentencias 7215-2014³ del 19 de enero de 2015, y 716-20134 del 13 de mayo de 2013.

Esta teoría no ha estado exenta de cuestionamientos, puesto que las situaciones en las que concurre el consentimiento y en aquellas en que no

3 La responsabilidad medica constituye, a su vez, un capítulo particular de la responsabilidad profesional; es decir, estrictamente contractual, salvo que se trate de supuestos de derecho penal. Este criterio es pacífico en la doctrina y en la jurisprudencia (considerando segundo).

4 "Que, en lo que atañe a la impugnacion, en el fallo objetado los sentenciadores dejan asentado el incumplimiento culpable del demandado de las obligaciones que le imponía el contrato de prestación médica y que, producto de la deficiente intervención quirurgica dental que practicó, fue dañado el nervio mentoniano de la actora, generándole una parestesia irreversible, con pérdida de sensibilidad permanente, estableciendo los jueces que tales molestias se transforman en un motivo de dolor síquico" (considerando tercero).

Esta obra está bajo una Licencia Creative Commons

Atribución-NoComercial-SinDerivar 4.0 Internacional, IIJ-UNAM.

Boletín Mexicano de Derecho Comparado, núm. 156, pp. 1575-1598. 
concurre en prestaciones médico-sanitarias puede generar consecuencias diferentes; así, por ejemplo, se está frente a un escenario diverso cuando se realiza una prestación que deviene de una relación contractual que cuando se atiende un paciente en urgencias (Pizarro 2008, 540). Se critica este tratamiento diferenciado, y en tal sentido propone un sistema unificado (Pizarro 2008, 540). Por otra parte, la jurisprudencia ha afirmado que puede existir un tratamiento diferenciado según el profesional contra el cual se dirija la acción, según lo resuelto por la sentencia de la Corte Suprema rol 9189-20175 del 31 de enero de 2018.

Sin perjuicio de que fundar la responsabilidad médica sanitaria en las normas de la responsabilidad contractual es la regla general en nuestro sistema jurídico, existen tendencias jurisprudenciales que se han centrado en que los daños causados en el ejercicio de una prestación médica se resuelvan según lo dispuesto en los artículos 2314 y 2329, inciso primero, del Código Civil chileno, que recogen la cláusula general alterum non laedere.

Desde el punto de vista de la responsabilidad extracontractual, la doctrina ha circunscrito su ámbito de aplicación a un espectro de supuestos de hecho más limitados; así, Court (1998, 281), siguiendo a Alessandri, señala que procede la aplicación de este estatuto:

a) cuando el médico causa daño al paciente a quien presta servicios por amistad o por espíritu caritativo o de beneficencia, sin ningún fin de lucro; b) si con la muerte o las lesiones ocasionadas al paciente causa daños a un tercero; y c) en general, cuando con cualquier acto de su profesión daña a un tercero con quien no está ligado contractualmente (Court 1998, 281).

5 "La recurrente reconoció formar parte del equipo médico del doctor Miranda Flieller, quien, por ende, eligió al personal que lo debía asistir en el procedimiento, debiendo colegirse entonces que existe un contrato entre ellos, puesto que el médico introdujo para el cumplimiento de su propia obligación contractual un tercero respecto del paciente, tercero que de este modo se constituye en un sujeto pasivo o deudor a quien le es exigible efectuar la prestación convenida, debiendo responder de los perjuicios originados por el incumplimiento íntegro de la obligación o de su cumplimiento tardío si ello se debe a su culpa o dolo. Por ello es que habiéndose optado por perseguir la responsabilidad contractual de la recurrente resulta ineludible precisar los deberes exigibles a la matrona para determinar si es posible imputarle una conducta razonablemente culposa que la ponga en situación de responder por su obrar en la ejecución del contrato" (considerando decimocuarto). 
La discusión al respecto no es sencilla, pues existe una confluencia de ambos sistemas que se resuelve por el tribunal de instancia que conoce y resuelve las demandas según se haya accionado de manera principal o subsidiaria. Así lo plantea Vidal, quien señala que no hay una visión unitaria al respecto, y reconoce la oscilación entre los sistemas de responsabilidad mencionados, llegando incluso a permitir a la víctima que elija la opción según la conveniencia que las normas particulares puedan entregarle (Vidal 2003, 2). Del mismo modo lo ha reflejado la jurisprudencia en sentencia de la Corte Suprema rol 38151-2016, ${ }^{6}$ del 25 de abril de 2017.

Por consiguiente, es procedente reflexionar en torno a la existencia de dos regímenes de responsabilidad confluentes en la actualidad, lo que genera los llamados cúmulos de responsabilidad, en virtud de los cuales el supuesto de hecho permite aplicar las reglas de responsabilidad contractual y extracontractual.

A primera vista, las posibles soluciones ante esta problemática es aplicar las reglas de la primera, argumentando que por un orden sistémico del Código Civil chileno éstas representarían la regla general, y que además tienen un tratamiento más profundo y detallado, o aplicar las reglas de la segunda, fundamentado en que normalmente las personas se vinculan sin un contrato de por medio, por lo que la regla general sería en realidad la responsabilidad extracontractual, y excepcionalmente existiría un vínculo contractual.

La jurisprudencia de la Corte Suprema ha indicado acertadamente en sentencia de rol 31061-2014 del 21 de marzo de 2016 que

De ahí, entonces que tratándose de responsabilidad civil médica... debilita la tajante distinción que tradicionalmente se ha hecho en nuestro ordenamiento jurídico, respecto de la responsabilidad contractual y la extracontractual,

$6 \mathrm{Al}$ respecto, se debe precisar que la responsabilidad médica, en términos generales, se rige por el estatuto contractual, puesto que en la generalidad de los casos el paciente habrá contratado los servicios del profesional elegido por él; sin embargo, tal circunstancia no excluye que la acción del médico tenga otra fuente y pueda generar responsabilidad extracontractual, presentándose incluso episodios de concurrencia de responsabilidades - cúmulo u opción de responsabilidades donde un mismo hecho puede ser calificado como incumplimiento contractual y también como ilícito extracontractual (cuasidelito de lesiones por mala práctica médica) - En esta situación se admite la opción de la víctima, por lo cual - en referencia al caso particular - el paciente pudo elegir el estatuto jurídico por el cual perseguir la indemnización (considerando tercero).

Esta obra está bajo una Licencia Creative Commons

Atribución-NoComercial-SinDerivar 4.0 Internacional, IIJ-UNAM.

Boletín Mexicano de Derecho Comparado, núm. 156, pp. 1575-1598. 
pues el contenido normativo no es tan diverso y en ambos estatutos existe un ilícito civil, dado por el incumplimiento al contrato o a las obligaciones que emanan de la ley.

Como se ve, la existencia de la responsabilidad civil médica posee muchas perspectivas, ya que en sí misma puede contener elementos de ambas clases de regímenes Ello plantea problemas que no son de fácil solución, y que ante hipótesis complejas, como el caso de la responsabilidad de los profesionales de la salud, puede generar más problemas a la hora de resolverlos adecuadamente.

\section{2. ¿Sistema objetivo o subjetivo de responsabilidad?}

Lo que distingue fundamentalmente a un sistema de otro es la imposibilidad de acreditar ausencia de culpa o dolo del autor del daño, y en definitiva se obligue a responder de los perjuicios causados. En tal sentido, los sistemas de atribución de responsabilidad del tipo subjetivo son los que predominan en los sistemas jurídicos contemporáneos, tomando en consideración la intención de quien realizó la acción u omisión dañosa. De tal forma, el sistema subjetivo se funda en la presencia de un comportamiento imprudente o negligente contrario a la observancia de un deber general de cuidado esperado por las personas considerado como culpa, o bien por la existencia de una intención de causar el daño.

La responsabilidad objetiva es una excepción en el sistema jurídico chileno, puesto que sólo exige la concurrencia del daño y una relación causal entre el hecho generado y éste, para que exista la obligación de indemnizar a la víctima. A nivel del Código Civil chileno, sólo un par de normas (artículos 2327 y 2328 del Código Civil chileno) se refieren a este tipo de responsabilidad, ya que ha sido principalmente abordada a través de regulación específica. Ejemplos de ello son leyes sectoriales; así, el Decreto-Ley 2.222 de 1978, que atribuye tal régimen de responsabilidad al causante del derrame de hidrocarburos y sustancias nocivas en el mar, o la Ley 18.302 de 1984, que regula la seguridad nuclear, entre otros casos.

En el caso de los profesionales de la salud, no cabe duda de que debe seguirse un sistema subjetivo, puesto que éstos serán responsables sólo cuando hayan dejado de observar la conducta, diligencia y cuidado que puede exigirse en atención a las circunstancias del caso. De este modo, el 
grado de culpa al que están sujetos no admite una apreciación según los parámetros clásicos dados por el Código Civil, sino que deben responder a una culpa, que se apreciará en concreto, considerando que la preparación y conocimientos técnicos que los facultativos deben tener para asumir la responsabilidad en los procedimientos que requieren de su intervención hacen exigible a ellos un estándar más alto y técnico.

De manifiesto queda que la existencia de la culpa es un requisito de procedencia de la responsabilidad civil, al analizar la sentencia de la Corte de Apelaciones de Santiago, rol 14229-2017, del 18 de diciembre de 2018. ${ }^{7}$ Según los hechos establecidos como inamovibles en la causa, se determinó que durante una intervención quirúrgica se dejó dentro de la paciente una compresa que generó complicaciones, y posteriormente debió ser extraída en otra intervención destinada para esos efectos.

A nuestro juicio, no es posible atribuir responsabilidad a todo evento en las prestaciones médicas, puesto que carece de fundamento y de lógica sistémica en el ordenamiento jurídico. La responsabilidad objetiva, como quedó evidenciado en los ejemplos expuestos, tiene lugar en situaciones excepcionales que alteran el normal desarrollo de la vida y suponen una mayor exposición a los riesgos.

Por su parte, las prestaciones médicas pueden estar rodeadas de una incertidumbre, que en determinadas hipótesis las hace más riesgosas; pero en ningún caso vuelve responsables a los distintos intervinientes de la prestación sólo por existir el daño; en este sentido, debe comprobarse que se ha actuado con infracción de la lex artis que gobierna cada disciplina.

7 "En el caso sub lite el aludido protocolo de "Recuento de Compresas" aparece satisfecho sin observaciones, y es lo cierto que, como se ha dicho, tal formalidad se incumplió, pues no existe discusión en que una compresa quedó alojada al interior del cuerpo de la actora sin ser detectada por quienes debían hacerlo, debiendo recordarse que de acuerdo a lo dispuesto en el artículo 1547 del Código Civil, el incumplimiento de una obligación contractual se presume culpable y debe probar la debida diligencia o cuidado el que ha debido emplearla, lo que en este caso no aconteció. Pues bien, existe entonces un incumplimiento contractual de parte de Clínica Santa María S. A. a los deberes que le imponía el contrato de hospitalización, conforme a lo que ella misma reconoce, según se lee en el motivo anterior, serían sus obligaciones, las que contrariamente a lo afirmado por dicha entidad, no fueron cumplidas satisfactoriamente en este caso, dado que los procedimientos en uso para el conteo de las compresas no fue efectuado eficaz y diligentemente por quien en representación de ella debía cerciorarse de aquello, certificándose por escrito, además, la practica correcta de un protocolo mal realizado" (considerando noveno).

Esta obra está bajo una Licencia Creative Commons

Atribución-NoComercial-SinDerivar 4.0 Internacional, IIJ-UNAM.

Boletín Mexicano de Derecho Comparado, núm. 156, pp. 1575-1598. 
No obstante, en el caso de los prestadores de servicios de salud públicos se aplica mayoritariamente, mas no exclusivamente, la noción de culpa asociada al concepto de falta de servicio para determinar la procedencia o no de la acción indemnizatoria.

\section{3. ¿Diferencias en la responsabilidad de un prestador del sector público y privado?}

$\mathrm{Al}$ efecto, se produce una discusión doctrinaria con relación a este punto, puesto que se distingue según si el prestador de salud es un ente público o uno privado para aplicar el sistema objetivo o subjetivo de responsabilidad, respectivamente, tal como destaca Pizarro, quien señala que es necesario distinguir si el acto médico fue realizado por un hospital público o por un profesional que ejerce de manera libre su profesión. En el primer caso el estatuto que regirá la responsabilidad será el de falta de servicio contenido en la Ley 19.966 (Pizarro 2010, 540), mientras que en el segundo caso aplicaremos el estatuto de responsabilidad general, sobre el cual se ha profundizado previamente (Pizarro 2008; 255 Tapia 2003, 81).

Somos críticos respecto de esa afirmación, pues a nuestro criterio carece de sustento jurídico y plantea más problemas en la determinación de las reglas aplicables a este caso de daños. Dicha doctrina es insostenible desde el punto de vista del análisis económico del derecho, puesto que ningún Estado estaría capacitado para responder por todos y cada uno de los daños que se causen en los servicios de atención públicos aun con la posibilidad de repetir contra el culpable. No obstante, ésa no debe ser la única consideración para reflexionar sobre este particular, sino que es importante realizar un análisis más acabado de la situación (Tocornal $2014,30){ }^{8}$

A nuestro entender, no hay motivo alguno para distinguir (Cárdenas 2007, 806) el tipo de establecimiento en que se comete el hecho que genera un daño, ya que en ese sentido las normas de responsabilidad son extensivas, y la concurrencia de un hecho que con culpa o dolo ha sido

8 La actividad sanitaria de un establecimiento de salud es la misma, sea público o privado el recinto donde se prestó. La dignidad y los derechos de protección a la salud de sus pacientes también son iguales. El daño a la salud también es similar en el conjunto de seres humanos frente a determinadas acciones. ¿Qué justifica favorecer legalmente a unos y no a otros para obtener una indemnización que tiene su origen en un daño a la salud? 
el antecedente causal de un daño son supuestos de hecho suficientes para que se apliquen las normas de responsabilidad subjetiva, como ya fue analizado. En esta línea argumentativa, expresa Cárdenas (2007, 806):

De lo dicho se sigue que cuando el Estado efectúa actividades análogas a las que realizan los particulares - como precisamente sucede con los servicios de salud - , los principios que gobiernen la reparación de los daños ocasionados por dicha actividad no tienen razón de ser diferentes (artículo 19 No. 24 inciso 2o. C.Pol.) Tal vez sería preferible hablar de "derecho de daños" en lugar de 'responsabilidad civil', ya que esta expresión permite de mejor manera centrar la atención en el desarrollo de una teoría general de la reparación de los daños, con independencia de la personas o personalidad de quien los haya causado.

No obstante ello, la jurisprudencia ha conservado la dualidad de sistemas distinguiendo la calidad que detenta el sujeto pasivo de la acción fundamentado en la doctrina de la falta de servicio.

Así, el concepto de falta de servicio ha sido delimitado por la Corte Suprema en sentencia rol 2655-2005 del 20 de noviembre de 2005, el siguiente sentido: "Se dice que esto ocurre: a) cuando el servicio no funcionó debiendo hacerlo; b) cuando el servicio funcionó irregularmente, y c) cuando el servicio funcionó tardíamente y de la demora se ha seguido perjuicios" (considerando quinto). ${ }^{9}$

Por tanto, y como contrapunto de lo analizado en el estatuto de responsabilidad contractual o extracontractual, podemos concluir que se sigue una lógica distinta en los casos que quien produce el daño es un ente público, considerando además que las consecuencias de la falta de servicio implican la aplicación de una responsabilidad del Estado, por lo que en que caso de presentarse las tres hipótesis previamente referidas, a saber: cuando el servicio no funcionó debiendo hacerlo, cuando el servicio funcionó irregularmente, y cuando el servicio funcionó tardíamente, y de la demora se han seguido perjuicios, siempre que se genere un daño, el Estado responderá. Por consiguiente, la responsabilidad patrimonial del Estado

9 "Que, como lo ha resuelto reiteradamente esta Corte Suprema, la falta de servicio se produce cuando se presenta una deficiencia o mal funcionamiento del servicio en relación con lo que debería haber sido su comportamiento normal y que, naturalmente, se siga un daño de esa deficiencia o mal funcionamiento".

Esta obra está bajo una Licencia Creative Commons

Atribución-NoComercial-SinDerivar 4.0 Internacional, IIJ-UNAM.

Boletín Mexicano de Derecho Comparado, núm. 156, pp. 1575-1598. 
nace de la mera infracción de los deberes de cuidado o actuación que éste tiene (Román 2012, 45 y 46).

Finalmente, la obligación indemnizatoria se describe en el considerando vigésimo de la Sentencia de la Corte Suprema rol 10254-2017, del 9 de agosto de 2017:

A su vez, este Tribunal antes ya ha dicho, respecto del artículo 38 de la Ley No. 19.966, que una atenta lectura del precepto permite concluir "que para que nazca la responsabilidad en materia sanitaria deben concurrir copulativamente los requisitos establecidos expresamente en la mencionada norma, esto es, la existencia de falta de servicio del respectivo Servicio de Salud, que haya causado un daño y que éste sea imputable al mismo. Ello es claro, pues la norma en comento señala justamente en su inciso 2o. que se debe acreditar - en este caso por los actores - que el daño se produjo por la acción u omisión del órgano, mediando falta de servicio" (Corte Suprema, Rol 3552010, 30 de julio de 2012, considerando décimo tercero).

Las diferencias procedimentales y probatorias a las que la víctima debe someterse son considerables en atención a si el agente causante del daño es un ente público o privado. No obstante, y a pesar de que la existencia de dos regímenes de responsabilidad pueda parecer provechosa en ciertos casos, mantenemos la posición de que es preferible establecer una única regulación al respecto, ya que si analizamos nuevamente el supuesto de una atención de urgencia, en que una persona concurre al prestador de salud más cercano sin tener posibilidad alguna de elegir en atención a que la espera puede significar un perjuicio mayor ¿se estaría sancionando con una carga más o menos, desde un punto de vista procesal, a aquella persona que debe probar la existencia de una falta de servicio?

De tal forma, las mayores dificultades que se observan en virtud de esta regulación se detectan en los casos en que se debe responsabilizar al Estado. Dicho esto, el panorama para el ejercicio de acciones contra los prestadores privados de servicios de salud no está exento de dificultades.

Por otra parte, esta situación también plantea dificultades innecesarias para la aplicación de la mediación obligatoria, distinguiendo la calidad del prestador; así:

La ley establece condiciones diferentes, para el sector público y privado, para acceder a la mediación, alterando los principios básicos de universalidad, 
igualdad y equidad. Entre otras diferencias se encuentran: la mediación pública es gratuita no así la privada y la limitación de montos indemnizatorios, solo aplicable a los prestadores estatales con el consiguiente perjuicio de los usuarios pertenecientes al sistema público de salud. La restricción de los montos a pagar, en todo caso, es congruente con lo ya dicho: cualquier acuerdo que supere dicha cifra, por su envergadura, se sustrae de la mediación. Las partes pueden voluntariamente abandonar el proceso de mediación, en cualquier etapa previa al acuerdo. En contrario, la mediación privada no establece montos ni límites quedando estos liberados a la decisión de las partes (Milos 2014, 99 y 100).

Reiteramos las críticas y fundamentos que al respecto ya se han señalado, puesto que nuevamente se crea una distinción injustificada que ante unos mismos hechos aplica un estatuto diferente, que conllevará en resultados distintos para las víctimas.

\section{NOTAS PARTICULARES DE LA RESPONSABILIDAD MÉDICO-SANITARIA}

Las normas sobre responsabilidad, tanto contractual como extracontractual tienen aplicación general; pero su aplicación ante casos más complejos revela los límites de ésta. La fecha del Código Civil chileno dan a este cuerpo normativo una vigencia de más de 160 años, lo que aparejado a la inexistencia de alguna modificación profunda sobre la materia implican que la complejidad que supone un daño en el contexto de una prestación médico-sanitaria no esté comprendido en nuestra regulación.

Ante esto, la mediación sanitaria parece ser una alternativa beneficiosa a la hora de evitar la complejidad a la que se ven sometidas las partes en un litigio de esta índole, con el objetivo de obtener la reparación del daño sufrido, considerando especialmente que se trata de materias tan sensibles como la salud, la integridad física, psíquica, e incluso la vida de las personas.

Analizaremos algunas de las particularidades de la responsabilidad médico-sanitaria para generar un panorama amplio de los beneficios que este mecanismo alternativo de resolución de conflictos puede generar. 


\section{Sujeto activo del daño y diligencia debida}

En la responsabilidad extracontractual se discute si la culpa se gradúa según las reglas generales o si se responde de un mismo grado de culpa, que corresponde a la diligencia exigible al estándar de un buen padre de familia. Junto con ello, la discusión se mantiene si la culpa debe analizarse en concreto o en abstracto.

Creemos que en estos casos es necesario ir más allá de una simple apreciación según las normas generales, puesto que el sujeto activo del daño es particular, ya que su estándar de diligencia está por sobre una mera obligación de no generar daño, pues además debe ajustarse a las normas técnicas de la disciplina que ejerce, no siendo sólo relevante el resultado que obtenga, sino también los métodos que utilice para concretarlo, y de ello deviene la responsabilidad civil profesional.

Determinar que un médico ha infringido la lex artis es un tema probatorio, que es particularmente complejo ante la existencia de procedimientos y técnicas conocidos sólo por especialistas. Sin perjuicio de ello, la determinación realizada por la jurisprudencia de este concepto permite tener un acercamiento más concreto a las hipótesis que pueden implicar una transgresión de dicho estándar:

Que ya trasladándose al ámbito de la responsabilidad profesional, en particular de la responsabilidad médica, se dice que las acciones de salud corresponde sean desarrolladas conforme a la Lex Artis Médica, que constituye el parámetro de comparación de la actividad desplegada por los médicos, caracterizada como una obligación de previsión, asistencia, diligencia, cuidado y garantía del respectivo facultativo. A lo anterior se añade, como patrón de comparación, que dicha prestación se realice en los términos exigidos para un profesional médico promedio, que se eleva cuando se está ante un especialista, puesto que en este caso se evalúa como un especialista promedio (Vargas 2007, 28). ${ }^{10}$

10 Sentencia de la Corte Suprema rol 7215-2014, del 19 de enero de 2015, considerando séptimo. Es interesante considerar que dentro de los deberes de la lex artis se encuentra también el deber de informar acerca del diagnóstico al paciente; el deber de continuar con un tratamiento; el deber de informar la necesidad de someterse a análisis preventivos. 


\section{Manifestación del daño}

El momento en que los efectos del hecho dañoso se hacen notar determina la oportunidad en que la acción indemnizatoria comienza a estar disponible, y, por consiguiente, el cómputo de la prescripción extintiva se inicia.

En el caso de intervenciones quirúrgicas, dichas consecuencias pueden manifestarse mucho tiempo después. Recurrentes son los casos en que en virtud de una intervención de carácter invasivo han quedado instrumentos utilizados por los facultativos dentro del cuerpo de los pacientes, pero las molestias se presentan varios años después de haber tenido lugar la intervención.

Ante una aparente prescripción de la acción indemnizatoria y la injusticia que una situación como la relatada produciría para la víctima, se ha realizado una interpretación normativa conforme a los fundamentos o principios de la responsabilidad desde una óptica general.

En efecto, uno de los fundamentos de la responsabilidad como principio general del derecho es la existencia del daño y su posterior reparación, ante lo cual la acción sólo puede estar "disponible" para la víctima una vez que los daños se manifiesten, de tal manera que la víctima sea capaz de percibirlos con independencia del momento en que se hayan originado, ya que sin la existencia de un daño patente la acción que eventualmente podría intentarse carecería de fundamento.

Por consiguiente, el plazo de prescripción extintiva sólo podría comenzar a contarse desde la manifestación efectiva de las consecuencias de un actuar negligente según los estándares de la lex artis, puesto que la extinción de las acciones por el transcurso del tiempo tiene como base sancionar al actor que no es activo en el empleo de las herramientas que la ley le otorga para obtener su reparación, no siendo dable sancionar a quien no dispone de acción alguna. ${ }^{11}$

\section{Obligación de medios y de resultados}

Tradicionalmente, los médicos contraían obligaciones de medios en virtud de los servicios que debían prestar para curar al enfermo (Domín-

11 A propósito de la prescripción, véase la reciente sentencia de la Corte Suprema rol 19.130-2018 del 26 de diciembre de 2018. 
guez 2010; Vidal 2018, 26). Es preciso en esta clase de obligaciones atender a la lex artis, ya que el estándar para determinar si existe o no incumplimiento es haber utilizado todo aquello que en virtud de su conocimiento técnico se encontraba a su alcance según los procedimientos que deben seguirse en virtud de la disciplina en cuestión. Por ejemplo, se estableció como una transgresión de la lex artis:

La omisión de efectuar un diagnóstico diferenciado y derivar o recurrir a un médico especialista en ginecología, en concepto de los jueces, configura una infracción a la lex artis y, en definitiva, importa el incumplimiento del contrato celebrado entre las partes, obligando a los responsables a indemnizar los daños patrimoniales y morales que el fallo declara (sentencia de Corte Suprema rol 30907-2014 del 30 de marzo de 2015 considerando quinto).

Caracterizando la lex artis, la Corte ha indicado que

Se puede decir que aquella está constituida por el conjunto de principios y normas técnicas cuyo dominio es exigido a cuantos ejercen la actividad. Así, para establecer si un sujeto cumplió con aquellas, se considera como parámetro de control el comportamiento de un profesional medio ante análogos supuestos de hecho precisos y determinados, que importa ponderar las circunstancias específicas, en concreto a las que se vio enfrentado (sentencia de Corte Suprema rol 99898-2016 del 21 de diciembre de 2016, considerando quinto).

Ahora bien, en el caso de las obligaciones de resultado, estas obligaciones son de carácter concreto, no es posible excusarse probando ausencia de culpa (Ruz 2011).

Dicha circunstancia no debe ser un obstáculo que permita comprender que determinadas obligaciones médicas pueden tener esa categoría, dependiendo de la naturaleza de la prestación que se ofrece. Estudiar las múltiples dimensiones de un fenómeno como el de la responsabilidad médica puede ayudar a asumir los desafíos que ésta plantea, y que las alternativas a su resolución no están dadas necesariamente por una lógica judicial adversarial.

La importancia de esta distinción tiene que ver con la actividad probatoria que desempeñarán las partes y la valoración de los esfuerzos que realizarán, tal como lo define Cárdenas: 
En el ámbito nacional, a pesar de cierta vacilación de la jurisprudencia médica, por regla general la carga de la prueba de la culpa pesa sobre el paciente/acreedor (demandante), pues algunos tribunales, al catalogar la obligación del médico como una obligación de medios, han entendido inaplicable el 1547 del CC, "igualando de esta manera la regla contractual, la regla exlracontractual y la regla que se sigue en los casos en que es demandada la responsabilidad del Estado por la falta de servicio". Por vía excepcional, cuando la obligación médica es considerada una obligación de resultado, la culpa se presume "fuertemente" y la argumentación es apoyada en el expediente de los hechos negativos (que veremos más adelante), y en la regla contenida en el articulo 1547 inc. 3o., cuya aplicación - en estos supuestos - no deviene preterida (Cárdenas 2010, 64).

\section{Esfuerzos probatorios}

Sin lugar a dudas este es el aspecto más complejo a estudiar, los altos niveles de rigurosidad técnica, la asimetría en el acceso a la información y la existencia de cursos causales múltiples son algunos de los problemas que se presentan al tener que probar la responsabilidad médica facultativa. En este sentido explica Vidal $(2018,26)$ :

Por regla general, se ha sostenido que en materia médica la prueba de la culpa recae en la víctima. Sin embargo, por aplicación del principio de la igualdad de los medios probatorios entre médicos y paciente y la asimetría de información entre ambos, la jurisprudencia ha construido verdaderos deberes de colaboración que pesan sobre los médicos y se traducen en que el médico debe suministrar la información relacionada con aspectos de la ciencia médica.

Un medio de prueba relevante en estos casos será el informe de peritos, ya que los hechos de que trata suponen conocimientos especializados que difícilmente el juez y las partes conocerán.

$\mathrm{Al}$ efecto, el servicio médico legal es el órgano idóneo para informar en los litigios sobre la materia. No obstante que alguna doctrina ha efectuado reparos a su labor por una posible falta de objetividad en virtud de la llamada "solidaridad profesional", no compartimos esta desconfianza, como apunta Pizarro (2008, 542): 
Es usual que se señale que los peritajes no son siempre un medio idóneo atendida la solidaridad entre los médicos. Sin embargo, esa intuición contrasta con el trabajo efectuado por el departamento de negligencias médicas del Servicio Médico Legal, cuyos informes en no pocos casos resulta desfavorable para el profesional.

Bajo nuestra óptica, la desconfianza es consecuencia directa de la dificultad probatoria a que se ven sometidas las partes en un caso de este tipo, ya que la asimetría en el conocimiento de la información genera obstáculos a veces infranqueables a la actividad probatoria; sin embargo, como se indicaba, dicha asimetría está siendo aminorada por la construcción de la jurisprudencia nacional, que atribuye a infracción de los deberes de colaboración una presunción judicial de negligencia (Sentencia de la Corte Suprema 2013, rol 8307-2012). ${ }^{12}$

Larroucau detecta otra de las dificultades que en materia probatoria encontrará el actor, al profundizar en la noción del estándar de prueba:

Esto en la justicia patrimonial tiende a expresarse en la regla de probabilidad prevaleciente $(\mathrm{P}>0,5)$, la que denota el grado de confirmación de los hechos respecto de las pruebas disponibles. Y es aquí donde la justicia chilena exhibe, tal vez, sus mayores falencias: (i) por una parte, ella acude sin ningún reparo a la convicción del juez para consignar en la sentencia los hechos probados y, (ii) por otro lado, no distingue entre el estándar de prueba civil y el estándar penal cuando se fijan esos hechos. Este es un panorama que debe ser corregido, (i) ya que la convicción judicial - entendida como algo subjetivo - es un falso estándar, porque no informa de ninguna de las razones tomadas en cuenta para decidir que las evidencias confirmaban o no los hechos, de modo que acudir a ella contradice el sentido que tiene motivar el fallo y hace estéril cualquier recurso procesal que prometa una revisión de los hechos; en segundo término, porque las exigencias para establecer los hechos en que se funda una decisión sobre la responsabilidad civil no pueden ser medidas con la vara del Derecho penal (Larroucau 2014, 69).

Más allá de las reglas de qué se debe probar o quién debe probar, es necesario centrar el eje del debate en la dificultad material que presentan estos litigios debido a su alto contenido técnico y los obstáculos que esta situación puede significar a la orden de obtener una reparación de los da-

12 Sentencia de la Corte Suprema rol 8307-2012 (25 de noviembre de 2013). 
ños causados por falta de elementos que logren acreditar cursos causales puesto que el daño, en la mayor parte de los casos, sí existe.

\section{DE LA PÉRDIDA DE LA OPORTUNIDAD COMO RESPONSABILIDAD SANITARIA}

Una de las perspectivas de la falta de servicio se ha conceptualizado como la pérdida de la oportunidad, que interesa puntualizar para delimitar el alcance de la mediación obligatoria.

Naciendo desde una construcción jurisprudencial, se ha arribado a la determinación del concepto que atribuye responsabilidad al servicio de salud que no realiza diligentemente lo que debía hacer en atención a detectar una enfermedad o realizar un diagnóstico acertado, impidiendo con posterioridad que el paciente se mejore de tal condición.

En efecto, la principal particularidad es que en estos casos se realiza un juicio mayormente probabilístico sobre las consecuencias provocadas por un actuar negligente en la etapa de proyección de una enfermedad o afección. Así, la Corte Suprema ha establecido que

La negligencia del personal médico no estuvo en no haber acertado en su diagnostico, sino en no haber realizado aquello que era a todas luces imprescindible ante un caso como el que se le presentaba: ordenar y practicar oportunamente una ecotomografía o una radiografía abdominal (considerando 4o. del fallo de reemplazo).

También se detiene esta sentencia en las particularidades de la causalidad en materia médica, señalando que ella es más difícil de establecer, máxime "cuando el dilema es si en razón de una negligencia médica el paciente pudo perder una oportunidad de sanarse. En estos regímenes de responsabilidad muchas veces solo será posible efectuar una estimación de la probabilidad de que el daño se deba a un hecho o, como sucediỏ en este caso, al incumplimiento de un deber de atención eficaz y oportuna, por el cual el demandado deba responder" (considerando 7o. del fallo de reemplazo) (Ríos y Silva 2015, 167).

Por otra parte, la doctrina internacional ha puntualizado esta hipótesis al señalar que

En el ámbito de la responsabilidad civil hay casos en los que no puede establecerse si una determinada conducta ha provocado un daño, pero se da 
por bueno que, con el comportamiento debido, habría existido posibilidad de que el resultado lesivo no se hubiera producido - posibilidad u oportunidad, por tanto, de haber obtenido una ventaja o evitado una pérdida-. En el campo sanitario, suele conducirse a este campo los errores y/o retrasos en el diagnóstico y tratamiento de dolencias, la falta de información y/o de consentimiento informado y los erróneos o inexistentes diagnósticos prenatales (Barrocal 2011, 36 y 37).

No existe reconocimiento positivo de esta teoría en nuestra legislación, pero su estrecha relación con la falta de servicio y la existencia de una prestación que no se ha realizado de forma íntegra, o que de haberse prestado, ha sido de manera imperfecta por una carencia absoluta en el debido cuidado que los procesos técnicos de su disciplina imponen han sido las causantes de un daño que efectivamente pudo haberse prevenido o aminorado, entran en la categoría de responsabilidad y por tanto requieren de mediación obligatoria previa, siendo de interés para la aplicación de las consideraciones analizadas.

\section{CONCLUSiOnes}

1. La responsabilidad médico-sanitaria no posee en Chile una regulación sistémica. No existen en el Código Civil ni tampoco en una ley general, normas que se refieran latamente a esta clase de responsabilidad. La Ley 19.966, denominada Ley Auge, y la Ley 20.584 sobre los derechos y deberes del paciente, contienen disposiciones asociadas a responsabilidad.

2. La responsabilidad médico-sanitaria posee aspectos que pueden generar tanto responsabilidad contractual como responsabilidad extracontractual. Por lo tanto, esta clásica distinción no es aplicable en este tipo de responsabilidad.

3. El sistema subjetivo se funda en la presencia de un comportamiento imprudente o negligente contrario, y es este sistema el que predomina en nuestro ordenamiento jurídico. Sin embargo, en los casos de prestadores de servicio de salud público se aplica mayoritariamente, aunque no de forma exclusiva, el concepto de falta de 
servicio para determinar la procedencia o no de la acción indemnizatoria.

4. En Chile existen prestadores de servicio público y privado, lo que genera una serie de consecuencias en relación con los regímenes de responsabilidad aplicable. Si bien pueden avizorarse ventajas en mantener diversos regímenes, es menester indicar que la aplicación de estatutos jurídicos distintos no necesariamente implica un escenario más favorable para la víctima.

5. El sujeto activo del ilícito debe superar los estándares generales de diligencia, ya que debe ajustarse a la lex artis. La infracción de la lex artis es un tema probatorio complejo.

6. La manifestación del daño se determina por el momento en que los efectos del hecho dañoso surgen, y de este modo se genera la oportunidad en que la acción indemnizatoria comienza a estar disponible.

7. La categoría de obligaciones de medio y resultado para el ámbito de la responsabilidad médico-sanitaria es ampliamente aceptada. La importancia de esta distinción radica principalmente con la actividad probatoria.

8. En materia probatoria resultan novedosos los esfuerzos que ha realizado principalmente la jurisprudencia para construir verdaderos deberes de colaboración por parte del equipo médico.

9. La pérdida de oportunidad implica determinar si en razón de una negligencia médica la víctima perdió la oportunidad de sanarse; vale decir, fijar la probabilidad de que no se hubiera generado el daño sin el actuar negligente.

10. La existencia de un mecanismo alternativo de resolución de conflictos en la materia es positivo, ya que expande el abanico de opciones que puede tener la víctima a la orden de ser resarcido en los perjuicios causados.

\section{REFERENCIAS BIBLIOGRÁFICAS}

BArros Bourie, Enrique. 2010. Responsabilidad contractual y extracontractual, Santiago, Editorial Jurídica de Chile.

Berrocal Lanzarot, Ana. 2011. "A propósito de la responsabilidad civil médica. La teoría de la pérdida de oportunidad y del resultado o daño desproporcionado", Revista de la Escuela Médica Legal, 16.

Esta obra está bajo una Licencia Creative Commons

Atribución-NoComercial-SinDerivar 4.0 Internacional, IIJ-UNAM.

Boletín Mexicano de Derecho Comparado, núm. 156, pp. 1575-1598. 
CÁrdenas Villarreal, Hugo. 2007. "La responsabilidad patrimonial de la administración médico-sanitaria. Cuestiones y proyecciones", Estudios de Derecho Civil III, Valparaíso, Jornadas Nacionales de Derecho Civil.

Cárdenas Villareal, Hugo. 2010. "La cobertura dogmática de la recepción jurisprudencial de la distinción obligaciones de medios/obligaciones de resultado (una aproximación a través de casos de responsabilidad médica)". Cuadernos de Análisis Furídico. Responsabilidad Médica, vol. 6. Santiago, Ediciones Universidad Diego Portales-Escuela de Derecho. CourT Murasso, Eduardo. 1998. "Responsabilidad civil médica", Revista de Derecho de la Universidad Católica de Valparaíso, 19.

CORRAL TALCiAnI, Hernán. 2011. Lecciones de responsabilidad civil extracontractual, Santiago, Editorial Jurídica de Chile.

Domínguez Hidalgo, Carmen. 2010. "El problema de la culpa presunta contractual y las obligaciones de medio y las obligaciones de resultado: sus implicancias para la responsabilidad médica”, Cuadernos de Análisis Jurídico 3.

LARrouGaU TORRES, Jorge. 2014. “¿Cómo se prueba la responsabilidad médica en la justicia chilena?", Revista de Derecho, 2(XXVII).

Milos, Paulina. 2014. "El procedimiento de mediación establecido en la Ley No. 20.584 en Derechos y deberes de los pacientes", Estudios y textos legales y reglamentarios, Colombia, Universidad de los Andes.

NASSER, Marcelo. 2014. "La ley de derechos y deberes de los pacientes y la protección al consumidor", Derechos y deberes de los pacientes. Estudios y textos legales y reglamentarios, Colombia, Universidad de los Andes.

PARra SePúlvedA, Darío. 2014. La responsabilidad civil del médico en la medicina curativa (tesis doctoral), disponible en: https://e-archivo.uc3m.es/bitstream/handle/10016/19232/dario_parra_tesis.pdf? sequence $=1$.

Pizarro Wilson, Carlos. 2008. "Responsabilidad profesional médica. Diagnóstico y perspectivas", Revista Médica Chile, 4(136).

PizARro Wilson, Carlos. 2010. "Controversias jurisprudenciales de la responsabilidad de los servicios públicos de salud", en Responsabilidad Médica, Cuadernos de Análisis Jurídico.

Ríos, Ignacio y SiLva, Rodrigo. 2015. "La teoría de la pérdida de la oportunidad según la Corte Suprema", Revista de Derecho-Escuela de Postgrado (7). 
Román, Cristian. 2012. "Responsabilidad patrimonial de la administración por falta de servicio (responsabilidad objetivada)", Derecho Público Iberoamericano 1.

Rosso Elorriaga, Gian. 2012. "Aplicabilidad de la Ley del Consumidor a las intervenciones corporales con fines de embellecimiento", Estudios de Derecho Civil VIII, fornadas Nacionales de Derecho Civil, Santiago, Legal Publishing.

Ruz LÁRTIGA, Gonzalo. 201 1. Explicaciones de derecho civil. Obligaciones, t. II, Santiago, Legal Publishing.

TAPIA RODRÍGUEZ, Mauricio. 2003. "Responsabilidad civil médica: riesgo terapéutico, perjuicio de nacer y otros problemas actuales", Revista de Derecho (Valdivia) (15).

TOCORnAL GOOPER, Josefina. 2014. La responsabilidad civil de clínicas y hospitales, Santiago, Legal Publishing.

VARgas ARAVEna, David. 2007. "Responsabilidad civil médica por falta de información en algunos casos de wrongful conception a tenor de la jurisprudencia española", Gaceta Furídica, Santiago, 314.

VIDAL Olivares, Álvaro. 2003. "La responsabilidad civil del profesional médico", Revista de Derecho 8.

VIDAL OlIVARES, Álvaro. 2018. Responsabilidad civil médica. Cuadernos Furídicos de la Academia Fudicial, Santiago, Editorial DER. 